\title{
Fitossanitários e doenças hepáticas: Um desafio à saúde pública no Brasil
}

\author{
Phytosanitary and hepatic diseases in Brazil: A public health challenge in Brazil \\ Productos fitosanitarios y las enfermedades hepáticas: Un desafío para la salud pública en Brasil
}

Recebido: 03/07/2021 | Revisado: 09/07/2021 | Aceito: 12/07/2021 | Publicado: 23/07/2021

\author{
Letícia Ramos Molica \\ ORCID: https://orcid.org/0000-0001-7973-1428 \\ Universidade Estadual Paulista, Brasil \\ E-mail: leticia.molica@unesp.br \\ Indyanara Inácio Barreto \\ ORCID: https://orcid.org/0000-0001-8724-3299 \\ Universidade Estadual Paulista, Brasil \\ E-mail: indyanara.barreto@unesp.br \\ Karen C. M. Moraes \\ ORCID: https://orcid.org/0000-0002-6838-8393 \\ Universidade Estadual Paulista, Brasil \\ E-mail: kcm.moraes@unesp.br
}

\begin{abstract}
Resumo
A saúde pública de uma população depende de seus costumes, de sua genética e do meio ambiente em que se insere. No Brasil, a política econômica dependente do agronegócio estimula a utilização de fitossanitários e/ou defensivos agrícolas, o que pode ser negativo ao equilíbrio de ecossistemas e à saúde de sua população. Esses compostos químicos tiveram seu uso difundido na chamada Revolução Verde na década de 1960. No território brasileiro vários defensivos agrícolas são vendidos que, além do controle de pragas agrícolas, causam danos ao meio ambiente e a organismos não-alvo. Considerando-se as anomalias que acometem a saúde da população, as doenças hepáticas podem ser causadas pelo uso indiscriminado de fitossanitários. Caracterizadas pela Organização Mundial da Saúde como uma das 10 causas primárias de morte em diferentes países, essas anomalias possuem várias etiologias entre as quais a exposição a drogas e a toxinas ambientais. Uma vez estabelecido o quadro clínico das anomalias hepáticas, estas podem progredir a quadros mais deletérios e até mesmo conduzir os indivíduos ao óbito. Embora muito estudada, tratamentos realmente eficazes no controle e/ou cura das doenças hepáticas se embasam na alteração do estilo de vida, como a redução da exposição a compostos químicos. Nesse contexto, a atenção às políticas públicas e aos hábitos populacionais na utilização dos fitossanitários pode ser considerada uma importante aliada no controle e/ou prevenção do surgimento de doenças hepáticas. No presente estudo, abordaremos aspectos gerais sobre os fitossanitários mais utilizados no Brasil, assim como seus efeitos adversos à saúde hepática da população.
\end{abstract}

Palavras-chave: Biossegurança; Doenças do fígado; Educação da população; Pesticidas; Legislação.

\begin{abstract}
The public health system of a population depends on its habits, genetics and the environmental conditions. In Brazil, the economic politics is dependent on the agrobusiness, which supports the utilization of phytosanitary and/or agriculture defensives, which may be negative to the ecosystem and to the population health conditions. Those chemical compounds became accepted worldwide during the Green Revolution at the 60's. In Brazil several agriculture defensives are sold, which controls agriculture plagues; however, they cause damages to the environment and to the non-target organisms. Then, considering the pathologies that affect people, hepatic diseases can be caused by the indiscriminate use of phytosanitary. Those pathologies are classified by the World Health Organization as one of the top 10 causes of deaths in different countries, caused by different etiologies and, among them, drugs and environmental toxicants have to be considered. As the liver pathologies establishes in a body, those anomalies may progress to a more deleterious state and even cause patient's death. However, no effective treatment is available to the hepatic diseases. The only recommended procedure to reduce the symptoms of the disease is the change of life style, as the reduction of chemical compounds exposition. In this context, more attention to the public politics and population habits in using phytosanitary have to be considered as an important tool to control and/or revert liver diseases. Then, in this study, we present the agriculture defensives largely used in Brazil, as the adverse side effects of the chemicals to the hepatic health.
\end{abstract}

Keywords: Biosecurity; Liver diseases; Population education; Pesticides; Legislation.

\section{Resumen}

La salud pública de una población depende de sus costumbres, de su genética y del entorno en el que está incluida. En Brasil, la política económica dependiente de los agronegocios incentiva el uso de pesticidas fitosanitarios y/o 
agrícolas, lo que puede ser negativo para el equilibrio de los ecosistemas y la salud de su población. Estos compuestos químicos tuvieron su uso generalizado en la llamada Revolución Verde en la década de 1960. En Brasil, se venden varios plaguicidas agrícolas que, además del control de plagas agrícolas, causan daños al medio ambiente y a organismos que no son el objetivo. Considerando las anomalías que afectan la salud de la población, las enfermedades hepáticas pueden ser causadas por el uso indiscriminado de productos fitosanitarios. Caracterizadas por la Organización Mundial de la Salud como una de las 10 principales causas de muerte en diferentes países, estas anomalías tienen varias etiologías, incluyendo la exposición a fármacos y toxinas ambientales. Una vez que se establece el cuadro clínico de las anormalidades del hígado, pueden progresar a condiciones más perjudiciales e incluso llevar a individuos a la muerte. Aunque ampliamente estudiados, los tratamientos realmente eficaces en el control y/o la cura de enfermedades hepáticas se basan en el cambio de estilo de vida, como la reducción de la exposición a compuestos químicos. En este estudio, la atención a las políticas públicas y hábitos de la población en el uso de productos fitosanitarios puede considerarse un aliado importante en el control y/o prevención de la aparición de enfermedades hepáticas. En el presente estudio, abordaremos aspectos generales sobre los fitosanitarios más utilizados en Brasil, así como sus efectos adversos sobre la salud hepática de la población.

Palabras clave: Bioseguridad; Educación de la población; Enfermedades del hígado; Plaguicidas; Legislación.

\section{Introdução}

A saúde pública de uma população depende de seus costumes, de sua genética e do meio ambiente em que se insere. No Brasil, a política econômica dependente do agronegócio estimula a utilização de fitossanitários e/ ou defensivos agrícolas em grandes quantidades, o que pode ser negativo ao equilíbrio de ecossistemas e a saúde de sua população evidenciado nas últimas décadas (Lopes \& Albuquerque, 2018; Silverio \& Pinheiro, 2019). Entre as anomalias que afligem os trabalhadores, as doenças hepáticas se despontam. Caracterizada pela Organização Mundial da Saúde (OMS) como uma das 10 causas primárias de morte em diferentes países (WHO, 2020), as doenças hepáticas possuem diversas etiologias entre as quais a exposição a drogas e a toxinas ambientais (Armstrong \& Guo, 2019). Uma vez que se estabeleça, as anomalias hepáticas podem progredir a quadros clínicos mais severos e até mesmo conduzir os indivíduos ao óbito, sendo esses fatos cada vez mais recorrente no Brasil (Ramai et al., 2021), considerando-se a escassez de tratamentos eficazes no controle e/ou cura dessas anomalias. Nesse contexto, a atenção às políticas públicas em seus mais variados aspectos e aos hábitos populacionais pode ser considerada uma importante aliada no controle e/ou prevenção do surgimento de doenças hepáticas na população. No presente estudo, iremos abordar aspectos gerais sobre os fitossanitários mais utilizados no Brasil, assim como seus efeitos adversos à saúde hepática da população.

\section{Metodologia}

O estudo, trata-se de uma revisão da literatura sendo, portanto, de natureza qualitativa, elaborado com enfoque de se combinar informações relevantes sobre os fitossanitários e a participação dos mesmos como um agente indutor de patologias hepáticas. De acordo com alguns autores a revisão bibliográfica é elaborada com embasamento em estudos existentes e divulgados em livros, monografias e revistas especializadas sob forma de artigos científicos (Gil, 2008; Gil, 2010), visando compilar informações relevantes sob os aspectos investigados. O levantamento de informações sobre o assunto em investigação foi realizado utilizando-se base de dados nacionais e estrangeiros em língua inglesa sobre a temática em questão. Foram avaliados trabalhos em base de dados Web of Science, Scientific Eletronic Library Online (Scielo), National Library of Medicine (Pubmed) e repositórios institucionais das Universidades brasileiras. O período da pesquisa foi livre e todas as informações foram inicialmente consideradas, pois objetivamos buscar a evolução do conhecimento sobre a utilização de fitossanitários e seus efeitos negativos à saúde pública e as doenças hepáticas. Os artigos mais recentes (condizentes aos 10 últimos anos) despontaram em nossas análises demonstrando uma maior conscientização da população sobre a temática em questão. Pelo fato de ser uma investigação qualitativa, a interpretação das informações por parte dos pesquisadores e mesmo as opiniões dos autores são expostas ao longo do estudo, embasando-se nas orientações de Pereira et al (2018). 


\section{Desenvolvimento e Discussão}

\subsection{Fitossanitários e sua utilização em terras brasileiras}

Os agrotóxicos, também conhecidos como praguicidas, pesticidas, fitossanitários, dentre outros, são compostos químicos que controlam, destroem ou previnem, de forma direta ou indireta, patógenos presentes em animais e plantas de interesse humano (Almeida et al., 2017; Mendes et al., 2019; Mejía-Carmona et al., 2020). Esses compostos são classificados em quatro grandes famílias: os organofosforados, os carbamatos, os organoclorados e os piretróides (Almeida et al., 2017; Mendes et al., 2019).

Os organofosforados são ésteres derivados de ácido fosfórico e se caracterizam como uma classe de agrotóxico que promove a hiper excitação neural decorrente da inibição e degradação da acetilcolinesterase, levando a crises colinérgica em organismos alvos (Mukherjee \& Gupta, 2020). Esses compostos vêm sendo utilizados em grande escala desde meados do século XX. Agindo de forma semelhante, os pesticidas do tipo carbamatos (ésteres do ácido carbâmico) formam um complexo menos estável e reversível com a acetilcolinesterase, apresentando um efeito limitado entre 12 h e 48 h, sessando seu efeito nos organismos (Mendes et al., 2019). Paralelamente, assim como os organofosforados, os organoclorados possuem uma alta toxicidade aos humanos, provocando uma série de sequelas agudas ou crônicas, como danos neurológicos nos organismos alvo. Entretanto, no Brasil os pesticidas da classe organoclorados foram substituídos pelos organofosforados pois são considerados menos agressivos ao meio ambiente (Vilca et al., 2017; Ferreira et al., 2018). Por sua vez, temos os piretróides, que são os mais antigos dos pesticidas utilizados, pois foram originalmente extraídos de compostos naturais, piretrinas, produzidas por plantas do "gênero" Pyrethrum (Chrysanthemum cinerariaefolium). Atualmente, esses fitossanitários são sintetizados quimicamente e além de reduzirem a atividade da acetilcolinesterase eles atuam em canais de $\mathrm{Na}^{+}$dependente de voltagem, causando despolarização das células nervosas, excitação neuronal e morte do organismo alvo. Além disso, o agroquímico pode reduzir a ação da enzima citocromo P450 no fígado e alterar o sistema de detoxificação do organismo (Hołyńska-Iwan \& Szewczyk-Golec, 2020). Essa classe de compostos é utilizada com maior incidência no controle de insetos e pragas domésticas, onde estudos apontam um menor impacto ambiental pela sua utilização, visto que são usualmente decompostos pela luz do sol. Entretanto, esses compostos químicos vêm alterando a resistência de insetos, que favorece a um desequilíbrio ambiental o que requer maior cautela na sua utilização (Matsuo, 2019).

Historicamente, os fitossanitários foram desenvolvidos durante o período das guerras mundiais para serem utilizados como estratégia de destruição de tropas inimigas. Entretanto, durante a chamada "Revolução Verde", que teve suas origens nos Estados Unidos da América (EUA), muitos dos fitossanitários passaram a ser utilizados na agricultura na forma de defensivos agrícolas com o propósito de aumentar a quantidade de alimentos no período pós-guerras mundiais (Porto \& Soares, 2012; Lopes \& Albuquerque, 2018; Vasconcellos et al., 2019). Para isso, ocorreu a modernização da agricultura frente as inovações tecnológicas e o desenvolvimento de maquinário, sementes mais resistentes e intensiva utilização e desenvolvimento de insumos químicos. Consequentemente, monoculturas foram expandidas, contribuindo com a economia de diversos países, inclusive a do Brasil (Lopes \& Albuquerque, 2018), implementando um modelo agronômico conflitante com as culturas tradicionais locais (Pozzetti et al., 2019). No Brasil, os conhecimentos populares de manejo da terra, onde os alimentos são cultivados de acordo com as características dos biomas nacionais, não foram considerados. Optou-se pela expansão agrícola para as regiões do cerrado por meio de técnicas de correção da acidez do solo, acarretando em sérios impactos ambientais e problemas à saúde da população (Dutra \& Souza, 2017; Pozzetti et al., 2019).

Em solo brasileiro, a implementação de agrotóxicos nas lavouras se acelerou a partir do ano de 1960, principalmente nas regiões Centro-Oeste, Sul e Sudeste. Essa intensificação ocorreu devido ao Programa Nacional de Defensivos Agrícolas (PNDA), que concedeu crédito agrícola e favoreceu às atividades rurais com a utilização de sementes tratadas, maquinário e agentes químicos (agrotóxicos e fertilizantes) (Lopes \& Albuquerque, 2018; Vasconcellos et al., 2019). Com esse modelo de 
agricultura, a produção de alimentos no Brasil se elevou consideravelmente nas décadas que se sucederam (Porto \& Soares, 2012; Mendes et al., 2019). Atualmente, o Brasil é um dos principais produtores agrícolas do mundo, mas, desde 2008 ocupa o primeiro lugar na classificação mundial de consumo de agrotóxicos (Lopes \& Albuquerque, 2018; Silverio \& Pinheiro, 2019; Lopes \& Albuquerque, 2021). Infelizmente, em terras brasileiras, os agentes químicos são utilizados em quantidades absurdamente maiores do que aquelas recomendadas pela União Europeia (EU) e outros países como, por exemplo, a utilização de malationa, no feijão (utilização 400 vezes maior que na UE), acetamiprimido, na batata (utilização 50 vezes maior que na UE) e mesmo o glifosato, agrotóxico de maior utilização no Brasil (utilização 200 vezes maior que em outros países) (Lopes \& Albuquerque, 2021). No Brasil, a região Sul consome aproximadamente 30\% de todo defensivo agrícola do país, nela se destacando o Estado do Paraná, que utiliza três vezes mais agentes químicos por hectares/ ano que a média dos outros estados brasileiros (Lopes \& Albuquerque, 2018), embora as maiores taxa de intoxicação pelos agentes químicos são encontradas nos Estados do Espírito Santo, Tocantins e Paraná (Lara et al., 2019).

De fato, em se tratando de Brasil, a utilização de fitossanitários propulsionou visíveis avanços na economia em consequência da tecnologia agrícola e a política de utilização de fitossanitários, mas hoje tem-se maior consciência de que seu uso inadvertido traz prejuízos consideráveis à saúde humana e ao meio ambiente em razão da sua toxicidade, capacidade de bioacumulação e persistência na natureza (Lopes \& Albuquerque, 2018; Santos \& Pereira, 2020). Para exemplificar, é observada a perca de biodiversidade em ambientes com carbamatos e organofosfatos, maior risco de aborto espontâneo em mulheres que são altamente expostas ao DDT, além de indícios que alguns fitossanitários possam desencadear várias patogenias metabólicas e mesmo neurodegenerativas (Sabarwal et al., 2018; Silverio \& Pinheiro, 2019). Esse uso exacerbado de agrotóxicos é favorecido pela flexibilidade da legislação, que propicia a liberação e o uso de compostos químicos que estão proibidos em outras nações, e pela frouxidão na fiscalização das normas estabelecidas no Brasil em 1989 (Lei nº 7.802/ 1989), normativa está altamente protetora da saúde humana e meio ambiente (Almeida et al., 2017; Lopes \& Albuquerque, 2021). Em 2019, por exemplo, 474 produtos químicos foram liberados para uso no Brasil (Lima \& Valverde, 2020), o que favorece a toxicidade ambiental e seus efeitos colaterais aos humanos. Portanto, é possível assumir que a segurança alimentar, direito garantido pela Constituição Federal brasileira, tornou-se inconsistente frente a liberação de novos agrotóxicos, cujos critérios de seletividade e autorização para uso não estão claros (Gusmão et al., 2018; Almeida et al., 2017; Lopes \& Albuquerque, 2021).

\subsection{Os fitossanitários mais consumidos no Brasil}

Embora não se haja total transparência sobre o consumo de fitossanitários utilizados no Brasil, o glifosato [N(fosfonometil) glicina] se destaca como sendo o agente químico mais consumido no país no ano de 2018 (Figura 1) (Pignati et al., 2017; IBAMA, 2020). De acordo com Gusmão et al. (2018), esse fitossanitário representou 40\% do total de agroquímicos utilizado nas plantações brasileiras (195.056,02 toneladas) seguido pela utilização do defensivo agrícola ácido diclorofenoxiacético também conhecido como 2,4-D (48 mil toneladas), do maconzeb (40 mil toneladas) e do fipronil (1,6 mil toneladas). Assim, considerando-se a toxicidade dos mesmos ao meio ambiente e aos animais, incluindo o homem, na sequência, serão apresentadas características gerais desses principais fitossanitários como uma maneira de alerta sobre a periculosidade dos mesmos. 
Figura 1. Representação quantitativa dos insumos agrícolas ativos mais vendidos no Brasil no ano de 2018.

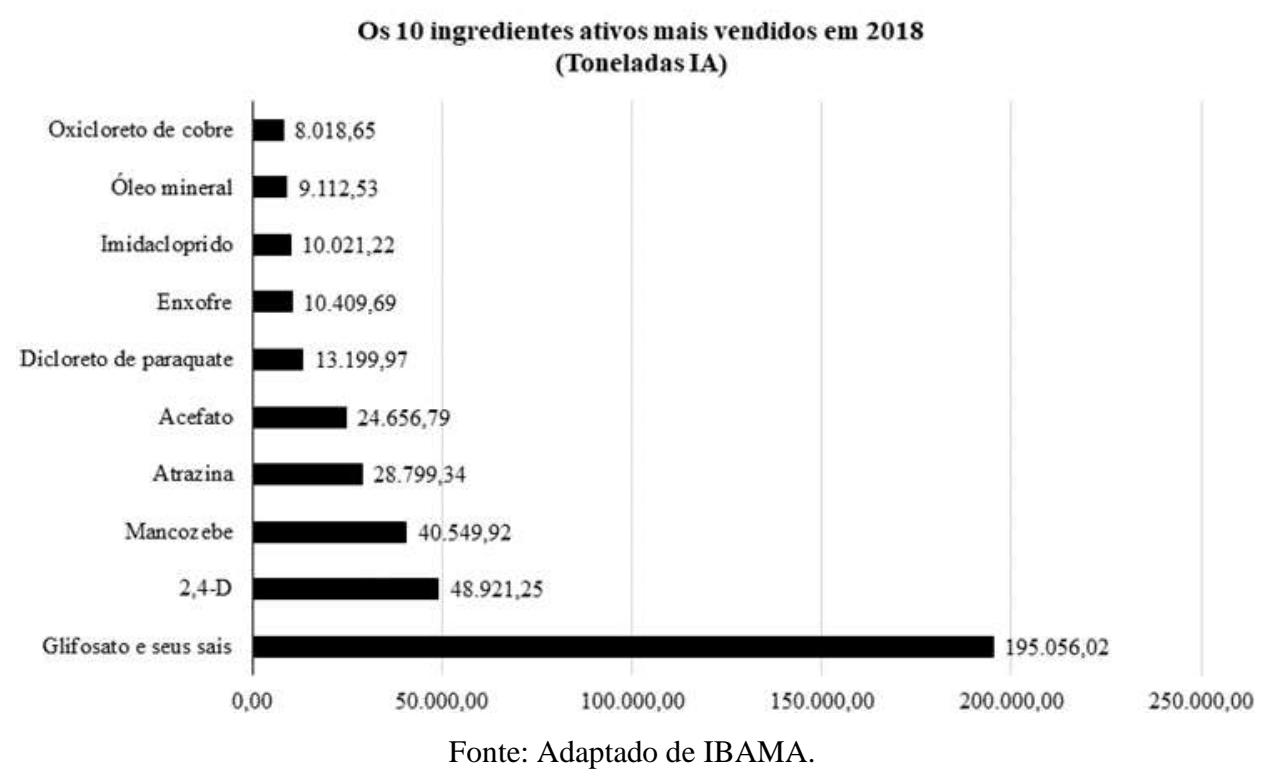

\section{- Glifosato}

Sintetizado em 1974 pela empresa norte-americana Monsanto, o glifosato, comumente comercializado pelo nome de Roundup ${ }^{\circledR}$ é um herbicida sistêmico não seletivo pertencente à família dos organofosforado (Zeng et al., 2020; Barbosa et al., 2020; Klingelhöfer et al., 2021). A partir dos anos 90 foi observado um aumento nas vendas de glifosato, o que pode ser explicado pela implementação de culturas resistentes ao pesticida nas principais regiões agrícolas do mundo. Outro fator que pode ter influenciado o aumento do consumo do herbicida foi a queda da patente da Monsanto em 1991, que viabilizou a elaboração de diversas formulações baseadas no glifosato por empresas concorrentes, lançando tais produtos no mercado mundial (Vicini et al., 2019). Em 2014 foram vendidos mais 826.000 .000 quilos de glifosato mundialmente, principalmente pelo seu baixo custo e amplo espectro de ação, sendo considerado o pesticida mais utilizado em todo o mundo e também no Brasil, como anteriormente abordado. Entretanto, com o aumento da resistência de ervas daninhas, supõem-se que o uso desse fitossanitário aumente ainda mais num futuro próximo (Barbosa et al., 2020; Zeng et al., 2020; Klingelhöfer et al., 2021).

Por se tratar de um herbicida sistêmico (Bonmatin et al., 2015; Lentola et al., 2020), o glifosato ao entrar em contato com tecidos e células vegetais impede a biossíntese de aminoácidos aromáticos essenciais, como a fenilalanina, tirosina e triptofano, por meio do bloqueio da 5-enolpiruvil-quiquimato-3-fosfato sintase (EPSP) da via metabólica do ácido chiquímico, presente nos cloroplastos (Vicini et al., 2019; Barbosa et al., 2020; Gonçalves et al., 2020; Klingelhöfer et al., 2021). Além de comprometer a síntese dos metabólitos primários pelo bloqueio da EPSP, o glifosato também afeta os metabólitos secundários, a fotossíntese, o estado nutricional e o fluxo de carbono da planta e outros microrganismos que também possuem a EPSP (Barbosa et al., 2020; Gonçalves et al., 2020). Ainda, por não degradar facilmente na natureza esse herbicida e seus metabólitos podem ser encontrados na água, no solo e até mesmo em alimentos processados com alta frequência, causando enormes prejuízos ao equilíbrio ambiental (Zeng et al., 2020; Gonçalves et al., 2020). Somando-se a isso, estudos relatam que culturas agrícolas não-alvo apresentaram contaminações pelo agroquímico devido as interações das micorrizas das plantações tratadas com o glifosato (Barbosa et al., 2020); outros estudos apontam os efeitos do pesticida em microrganismos do solo o que contribui negativamente com o equilíbrio ambiental e as interações do ecossistema (Gonçalves et al., 2020). Além disso, as plantas intoxicadas com o glifosato podem apresentar deficiência na absorção de minerais, assimilação de aminoácidos e na própria divisão celular (Cui et al., 2020), acarretando em plantas com menores valores de polifenóis, flavonoides, carotenoides 
e vitaminas C e E, quando comparadas a plantas cultivadas organicamente (Hurtado et al., 2019), evidenciando os efeitos negativos desse fitossanitário na qualidade do produto vegetal.

Em relação a saúde humana e animal, estudos apontam o potencial deletério do glifosato, uma vez que pode induzir danos genéticos e inibir a enzima do citocromo P450, atuando como um agente carcinogênico, além de reduzir a fertilidade de animais e quelar substâncias como ferro, cobalto e cobre, causando deficiências aos organismos alvo e não-alvo (Nascimento et al., 2019; Klingelhöfer et al., 2021). Também foi demonstrado a capacidade do glifosato transpassar a barreira hematoencefálica humana e de se acumular no cérebro e no líquido cefalorraquidiano (Zeng et al., 2020). Outros estudos apontam também a correlação entre o herbicida e o aparecimento ou o agravamento de algumas patologias como as doenças celíaca e a de Parkinson, a osteoporose, o hipotireoidismo, o glaucoma entre outras. Isso acontece, pois o glifosato é derivado do aminoácido glicina, que facilmente se insere numa variedade de vias metabólicas (Nascimento et al., 2019; Meftaul et al., 2020). Por seus efeitos deletérios, o herbicida é utilizado com restrição e/ou é proibido na União Europeia, assim como outros 149 defensivos agrícolas livremente comercializados no Brasil (Almeida et al., 2017; Lima \& Valverde, 2020).

Considerando-se o fígado como uma glândula mestra do organismo por sua característica metabolizadora (Chielle et al., 2015), desde os anos de 1980, estudos apontam os efeitos adversos do glifosato sobre o órgão (Mesnage et al., 2017; Pandey et al., 2019; Soudani et al., 2019; Mills et al., 2020; Portier, 2020). Entre os danos hepáticos causados pelo glifosato, o estresse oxidativo (Portier, 2020), mecanismos exacerbados de necrose (Mesnage et al., 2017), a inibição e/ou alteração do metabolismo energético mitocondrial (Portier, 2020), bem como disfunção do metabolismo de lipídios (Soudani et al., 2019) são apontados, os quais gradativamente colaboram com o acúmulo de gordura nos hepatócitos que podem desenvolver a doença hepática gordurosa não alcóolica (DHGNA) ou esteatose. Essa patologia causada pelo desiquilíbrio metabólico do organismo pode progredir a quadros de esteatohepatite, fibrose do órgão e até mesmo hepatocarcinoma (HCC) (Mesnage et al., 2017; Mills et al., 2020). Nos estudos realizados, baixas doses de herbicidas a base de glifosato foram capazes de alterar o metabolismo hepático de roedores, mesmo quando a administração de composto químico foi restrita a um intervalo de 2 semanas (Pandey et al., 2019; Mesnage et al., 2017), o que pode ser um fator negativo para a qualidade de vida de toda população.

No Brasil, apesar das evidências que apontam os inúmeros malefícios causados pelo uso exacerbado desse fitossanitário e da recomendação à proibição de seu uso pelo Ministério Público Federal, a Anvisa (Agência Nacional de Vigilância Sanitária) ainda não proibiu a sua utilização, o que se torna ponto de discussão, considerando-se os potenciais impactos deletérios de sua utilização ao ambiente e à saúde humana (MPF/DF 2015; Almeida et al. 2017; Nascimento et al. 2019).

\section{- 2,4-Diclorofenoxiacético}

Comercializado durante a década de 1940, o herbicida 2,4-diclorofenoxiacético (2,4-D) foi intensivamente utilizado em conjunto com o ácido 2,4,5-triclorofenoxiacético (2,4,5-T) na formulação do agente laranja, amplamente utilizado durante a guerra do Vietnã para desfolhar as árvores (Marcato et al., 2017; Zuanazzi et al., 2020). Atualmente, em razão de sua eficiência, valor acessível e seletividade é o segundo fitossanitário mais utilizado no Brasil (Marcato et al., 2017; Freitas et al., 2019), pois entra na composição de aproximadamente 1.500 herbicidas registrados (Freitas et al., 2019; Zuanazzi et al., 2020).

O fitossanitário 2,4-D imita o fito-hormônio de crescimento vegetal auxina, induzindo a biossíntese do etileno que, por sua vez, estimula a senescência foliar e a produção do ácido abscísico (ABA), o qual dificulta a divisão e expansão celular, eliminando plantas daninhas (Marcato et al., 2017; Freitas et al., 2019; Zuanazzi et al., 2020). A alta solubilidade do fitossanitário em água faz com que o 2,4-D e seus metabólitos sejam amplamente encontrados no meio ambiente, persistindo 
por tempo moderado. Além disso, dependendo das condições ambientais, o herbicida pode ser atingir lençóis freáticos e rios favorecendo as contaminações ambientais e o surgimento de doenças na população em geral (Zuanazzi et al., 2020).

Infelizmente, no Brasil, o herbicida 2,4-D vem sendo usado indiscriminadamente e em combinação com glifosato, para aumentar a eficiência no extermínio de ervas daninhas. Essa combinação de herbicidas atua negativamente na estrutura e funcionamento de microrganismos de água doce (Lozano et al., 2020) e nos humanos reforçam o aparecimento de disfunções metabólicas e outras anomalias como apontadas para o uso indiscriminado de glifosato (Freitas et al., 2019; Zuanazzi et al., 2020). Estudos apontam que no fígado o 2,4-D promove aumento nos níveis de estresse oxidativo e da peroxidação lipídica (Tichati et al., 2019; Shafeeq \& Mahboob, 2020), desregulando o metabolismo lipídico e o de carboidratos (Tichati et al., 2019). Em estudos realizados por Salla et al. (2019) foi observado que o 2,4-D age como um desacoplador de elétrons do metabolismo mitocondrial em fígado de ratos, diminuindo o potencial de membrana e a respiração celular pela inibição da flavoproteína succinato desidrogenase e do complexo citocromo C redutase. Além disso, o agente químico reduz os níveis de ATP de hepatócitos isolados, sendo considerado um inibidor do metabolismo energético.

\section{- Mancozeb}

Registrado pela primeira vez em 1948 nos Estados Unidos e liberado para o comércio em 1962, o mancozeb é o terceiro composto químico mais utilizado no Brasil (IBAMA, 2020), que vem sendo cada vez mais utilizado mundialmente. Isso decorre pelo seu baixo custo, eficácia contra aproximadamente 400 pragas diferentes, e por ser adotado no plantio de frutas e vegetais (Runkle et al., 2017; Bianchi et al., 2020). O mancozeb caracteriza-se como um fungicida de etileno bisditiocarbamato (EBCD) não seletivo com metabólitos etilenotiouréia (ETU), sendo sua toxicidade dada pela ativação de radicais livre em detrimento do sistema de defesa antioxidante, por meio da inibição da atividade enzimática (Aranha et al., 2021). Além disso, demonstrou-se que o fitossanitário atua bloqueando a formação de ergosterol, do citocromo C redutase ou a biossíntese da tubulina dos fungos, inviabilizando a propagação dos mesmos (Miranda, 2012). Entretanto, estudos apontam que animais não-alvo, inclusive os humanos são afetados pela toxicidade de curto prazo quando expostos a esse composto, principalmente ao ingerir alimentos ou água contaminados com mancozeb e/ou seus metabólitos (Seshoka et al., 2021). Trabalhadores rurais estão mais sujeitos aos danos que o fungicida pode causar à saúde, uma vez que eles podem ser contaminados ao inalar, ingerir, ou absorver pela derme esse químico (Runkle et al., 2017; Bianchi et al., 2020).

O mancozeb é um importante desregulador endócrino e está intimamente relacionado ao aparecimento de várias alterações metabólicas e fisiológicas entre as quais disfunções hormonais, danos ao desenvolvimento fetal, supressão do sistema imunológico, atividade mutagênica sobre células germinativas feminina, atuação neurotóxica induzindo a sintomas semelhantes aos do Parkinson, entre outras (Runkle et al., 2017; Bianchi et al., 2020; Bano \& Mohanty, 2020). Estudos apontam também os efeitos tóxicos de seus metabólitos no organismo, os quais podem causar danos no DNA (Bano \& Mohanty, 2020), aumentar a produção espécies reativas de oxigênio (EROS) (Bianchi et al., 2020), causar alterações no equilíbrio dinâmico do tecido hepático (Aranha et al., 2021), além de aumentar a proliferação desordenada de células e consequentemente o aumento da incidência de tumores malignos mamários, pancreáticos, na glândula tireoide, entre outros (Bianchi et al., 2020; Bano \& Mohanty, 2020; Aranha et al., 2021).

\section{- Fipronil}

O fipronil é um poderoso inseticida, pertencente à família dos fenilpirazol, desenvolvido pela companhia química e farmacêutica francesa Rhône-Poulenc por volta de 1987 e liberado para a comercialização em 1993 (Liang et al., 2019; Li et al., 2020). Aproximadamente 30\% dos agroquímicos sintetizados pelas indústrias em meados de 2008 eram representantes da ampla família dos inseticidas sistêmicos, neonicotinóides e fipronil (Bonmatin et al., 2015). Atualmente ele representa 10\% do 
mercado global de fitossanitários (Kim et al., 2019; Chang \& Tsai, 2020). No estado de São Paulo o fipronil e o herbicida 2,4D são os compostos químicos mais utilizados nas lavouras (Silva et al., 2020). A rápida e expoente adoção desse composto químico foi devido à resistência que insetos-pragas haviam adquirido as outras classes de agroquímicos disponíveis no mercado até então (organofosforados, carbamatos e piretróides), além de suas vantagens físico-químicas, quando em comparação a outros agrotóxicos, que viabilizou a sua utilização sob diferentes formas de aplicação (Leemans et al., 2019; Li et al., 2020).

Considerando-se as características do fipronil, ele passou a ser utilizado também no controle de pragas urbanas (baratas e cupins), aplicação veterinária (pulgas e carrapatos) e na piscicultura (Sadaria et al., 2019). Essa intensa utilização do herbicida, vem contribuindo para o seu acúmulo nos diferentes ecossistemas uma vez que o produto permanece no ambiente por considerável intervalo de tempo ( 1.000 dias em solos e sedimentos e até 1 ano em plantas lenhosas, por exemplo), aliado às sucessivas aplicações do fitossanitário nas plantações (Bonmatin et al., 2015; Liang et al., 2019; Li et al., 2020). Consequentemente, diversos ambientes e organismos não-alvo são atingidos pela toxicidade do fitossanitário, tais como solo, águas superficiais e subterrâneas, ar e invertebrados polinizadores, chegando a ser detectado em uma ampla variedade de ambientes por todo o mundo (Lentola et al., 2020).

Entre os organismos afetados pela utilização do fipronil no ambiente temos os insetos polinizadores. Nesses animais o fipronil bloqueia os canais de cloro presentes no receptor GABA (ácido $\gamma$-aminobutírico), causando seu acúmulo nas junções sinápticas e a interrupção da transmissão neural do organismo, levando a uma hiperexcitação nervosa e a morte (Liang et al., 2019; Silva et al., 2020; Li et al., 2020). No caso dos vertebrados, os efeitos imediatos do contato com os fitossanitários são menos evidentes devido a reduzida afinidade aos receptores neuronais desses animais (Zhang et al., 2018), o que favorece ainda mais a sua utilização em larga escala. Entretanto, para vertebrados, incluindo o homem, a toxicidade de metabólitos do fipronil como a fipronil-sulfona é 20 vezes maior do que a encontrada nos insetos, com vários casos relatados de intoxicação de animais e humanos pelo metabólito (Medeiros et al., 2015, Carrão et al., 2019; Li et al., 2020).

A fipronil-sulfona é o resultado da biotransformação hepática do fipronil por meio da enzima citocromo P450 que ocorre em diversos grupos de animais, como cães, ratos, gado e humanos (Roques et al., 2012; Medeiros et al., 2015). A inibição do citocromo P450 afeta o metabolismo hepático e, consequentemente, inibe o metabolismo energético mitocondrial. Outros autores demonstraram que o fipronil e seus metabólitos provocam mecanismos de apoptose, onde células do fígado sujeitas a baixas concentrações de fipronil ativam as enzimas caspase 3 e 7, ou ainda que a exposição crônica de mamíferos por via oral, resulta no aumento do peso do fígado e tamanho dos hepatócitos (Roques et al., 2012; Medeiros et al., 2015). Além disso, distúrbios na tireoide são frequentemente associados pela intoxicação causada pelo fipronil (Roques et al., 2012; Kim et al., 2019; Chang \& Tsai, 2020). Outros exemplos da toxicidade do fipronil e de seus metabólitos são encontrados na literatura. Alguns autores apontam que a exposição aguda ao agente químico causa dores de cabeça, náuseas, sudorese, vômitos, tontura, agitação e convulsões (Kim et al., 2019; Chang \& Tsai, 2020). Além disso, estudos com roedores apontou que o fipronil pode acarretar alterações no ciclo estral e diminuição da motilidade dos espermatozoides, assim como alterar a maturação neural da prole, devido a interferência direta no sistema GABAégico (Chang \& Tsai, 2020), reforçando a sua toxicidade.

Pelo conjunto das informações apontadas, reforçam-se as observações de que embora no Brasil grandes avanços na economia tenham sido alcançados frente ao incentivo de utilização de insumos agrícolas, sérias. consequências negativas para o meio ambiente e para a saúde humana são observadas. Isso se traduz em altos gastos com a recuperação de áreas degradadas, além da frequente aposentadoria por invalidez de trabalhadores rurais decorrentes da intoxicação pelos insumos agrícolas (Porto \& Soares, 2012; Almeida et al., 2017; Mesa, 2020). A utilização desmedida dos fitossanitários em áreas agrícolas colabora com o acúmulo dos mesmos em áreas de drenagem, cursos d'água e ambientes urbanos o que favorece o desequilíbrio 
ambiental e sanitário e a enormes prejuízos à sociedade como um todo (Lopes \& Albuquerque, 2018; Ismael \& Rocha, 2019; Zuanazzi et al., 2020; Barbosa et al., 2020).

Os fitossanitários afetam organismos em todos os seus biomas e um exemplo negativo da influência diretas desses compostos químicos é a extinção das abelhas ao redor do globo (Santos et al., 2018; Lentola et al., 2020). As abelhas estão diariamente sujeitas a intoxicação pelos agentes químicos, uma vez que consomem néctar, pólen e gotas de gutação de plantas silvestres que se desenvolvem na vizinhança de campos tratados com os fitossanitários. Em decorrência disso, observa-se uma considerável diminuição na longevidade, fecundidade e resistência a doenças, onde os fitossanitários afetam alguns genes relacionados à reação imune das abelhas sem ferrão, causando uma maior vulnerabilidade aos patógenos (GuimarãesCestaro et al., 2020), além de afetar o aprendizado, a navegação individual e a coleta de alimentos pelos animais (Neves et al. 2020; Lentola et al., 2020). Outros invertebrados não-alvo, assim como plantas, também podem sofrer os efeitos dos pesticidas, entretanto, a toxicidade dos fitossanitários a esses organismos é dependente da sensibilidade da espécie e do seu estágio do desenvolvimento (Lentola et al., 2020). Para os humanos, o desbalanço no meio ambiente acarreta em sérios prejuízos diretos e indiretos, tanto pelo aparecimento de pragas agrícolas como à saúde, como discutido a seguir.

\subsection{Saúde humana e os fitossanitários}

Atualmente, inúmeros estudos relacionam o aparecimento de doenças ao uso de agrotóxicos (Mesa, 2020; Lopes \& Albuquerque, 2021). Entretanto, os efeitos nocivos à saúde são dependentes de alguns fatores, como as características químicas do defensivo agrícola, da quantidade absorvida ou ingerida, do tempo de exposição e das condições gerais de saúde da pessoa exposta (Vasconcellos et al., 2019). Ao analisar esses aspectos, pode-se dividir os casos de intoxicação por agrotóxicos em agudos ou crônicos.

Os casos agudos de intoxicação são melhor estudados e possuem sintomas bem definidos como dores de cabeça, dermatites, náuseas, desorientação, dentre outros, que surgem no momento da exposição ou em até 24 horas (Vasconcellos et al., 2019; Mesa, 2020). Pesquisas pontuais mostram que a maioria dos casos de intoxicação aguda estão relacionados aos pequenos produtores, devido a carência de informações sobre os elevados riscos à saúde que o fitossanitário representa, associado a baixa assistência técnica para o uso correto de equipamentos e a não utilização dos equipamentos de proteção individual (EPI), entre outros, enquanto que efeitos crônicos da utilização dos agrotóxicos são geralmente associados aos trabalhadores rurais de grandes monoculturas (Porto \& Soares, 2012; Vasconcellos et al., 2019). Ainda, quando se trata de casos crônicos de intoxicação o estudo se torna mais complicado, uma vez que os sintomas podem aparecer em semanas, meses ou até mesmo anos após o contato com o agrotóxico (Vasconcellos et al., 2019; Neves et al., 2020) e serem responsáveis pelo aparecimento de diferentes comorbidades (Porto \& Soares, 2012; Mesa, 2020).

Independentemente do tipo de contaminação, a maioria dos trabalhadores rurais intoxicados são homens de idade adulta e com baixo nível de escolaridade, dificultando a percepção dos riscos, devido a leitura limitada dos rótulos; este não é o único fator para o uso incorreto, existe uma carência na área da segurança e saúde no trabalho (Porto \& Soares, 2012; Vasconcellos et al., 2019). Em estudos realizados com agricultores expostos constantemente a agentes químicos foram observados transtornos mentais, alteração nas atividades do telômeros, danos ao DNA e nos mecanismos de defesa das células, náuseas, dor de cabeça, anomalias no tecido hematopoiético e fígado, alteração nos níveis hormonais, depressão, mialgia, ansiedade, irritabilidade e maior chance de cometer suicídio (Lopes \& Albuquerque, 2021). Além disso, os fitossanitários são potenciais indutores de distúrbios metabólicos, que acarretam em síndromes complexas que podem prejudicar a qualidade de vida dos indivíduos acometidos (He et al., 2020). Segundo Taveira \& Albuquerque (2018), 70 mil pessoas morrem anualmente intoxicadas por agrotóxicos em países em desenvolvimento e 7 milhões de trabalhadores rurais adquirem doenças que comprometem a qualidade de suas vidas devido ao uso inadvertido de fitossanitários. Infelizmente, no Brasil há uma grande 
falta de informações que auxiliem no monitoramento real do trabalho agrícola (Faria, 2012). Em Lopes \& Albuquerque (2018), por exemplo, os autores descrevem um estudo populacional realizado entre os anos de 1999 a 2009 no Nordeste, que registrou quase 10 mil casos de intoxicação por agrotóxicos responsáveis pela morte de aproximadamente 2.052 indivíduos. Outro estudo relata 635 casos de intoxicação e 40 mortes causadas por fitossanitários no Estado da Paraíba num intervalo de seis anos (Ismael \& Rocha, 2019). Esses números alarmantes de casos de intoxicação sugerem alta toxicidade causada pelos fitossanitários em todo território brasileiro (Silvério et al., 2020).

Dentro dessa problemática e considerando-se a problemática mundial das doenças hepáticas, a utilização desmedida de fitossanitários está certamente contribuindo com o aumento dos casos, não somente no Brasil. Sendo o fígado o órgão responsável pelo metabolismo de xenobióticos e o detoxificador de diversas impurezas que alcançam os organismos (Chielle et al., 2015), cabe avaliar os danos hepáticos causados pelos fitossanitários e a sua correlação com o estabelecimento das doenças do fígado. Reforçando essa teoria, um estudo preliminar realizado com trabalhadores rurais do sul de Minas Gerais (Silvério et al., 2020) apontou a existência de hepatotoxicidade em 15\% dos participantes, apontado de maneira direta a correlação entre o uso de agrotóxicos e a saúde hepática da população em geral.

\subsection{Doenças hepáticas}

Como reportado, diversos órgãos e sistemas são afetados pela exposição aos fitossanitários, entretanto, por sua característica altamente metabolizadora, o fígado é o primeiro órgão a entrar em contato com a maioria dos xenobióticos que são absorvidos pelo organismo (Chielle et al., 2015). O fígado é o segundo maior órgão do corpo humano e desempenha funções importantes para a homeostase corporal, como a manutenção dos níveis de lipídeos e glicose, assimilação preliminar de nutrientes e o próprio metabolismo de substâncias tóxicas ingeridas (Chielle et al., 2015; Trefts et al., 2017). Isso se dá em decorrência do eixo intestino-fígado que viabiliza a troca de elementos da microbiota e do sangue por meio da veia hepática (Alamri, 2018; Ramos et al., 2021).

Mecanisticamente, a exposição aos fitossanitários, quer seja de maneira direta e/ou indireta, acarretam em alterações moleculares deletérias. Na detoxificação, a proteína citocromo P450 atua na redução/oxidação e hidrólise das substâncias tóxicas, tornando-as hidrossolúveis e, assim, facilitando sua excreção. Entretanto, a exposição do indivíduo a altas quantidades de fitossanitários, ou por um período prolongado, sobrecarregam o metabolismo, inviabilizando a detoxificação do órgão e conduzindo o mesmo ao desenvolvimento de quadros patológicos mais graves, como a esteatohepatite, caracterizada por desequilíbrio entre a captação, a síntese e a oxidação de lipídeos acarretando em descompensações metabólicas e o estabelecimento de um quadro inflamatório (Chielle et al., 2015; Armstrong \& Guo, 2019). Estudos recentes apontam que vários defensivos agrícolas, principalmente os que se caracterizam como poluentes orgânicos persistentes, bem como os produtos químicos orgânicos voláteis, metais, fumos e poeiras causam alterações metabólicas gerais nos humanos devido a descompensações endócrinas e hepáticas (Armstrong \& Guo, 2019; Wahlang et al., 2019; Nagaraju et al., 2020 a,b), contribuindo com o agravamento da fisiologia hepática.

Dentre as anomalias que acometem o fígado, a esteatose é a doença crônica mais comum em todo mundo, sendo caracterizada pelo acúmulo irregular de triglicerídeos, a níveis maiores que 5\% do peso do fígado (Qin et al., 2020; Ramos et al., 2021), decorrentes de alterações metabólicas, que desorganizam a homeostase intracelular e favorecem o acúmulo descompensado de gorduras pelos hepatócitos. A incidência da esteatose aumentou consideravelmente nos últimos anos devido, principalmente, ao estilo de vida populacional e a contaminação ambiental (Qin et al., 2020). Infelizmente, os quadros iniciais de acometimento do fígado nem sempre são identificados, o que favorece a progressão da patologia a quadros mais graves como a esteatohepatite, a fibrose, a cirrose hepática e, em alguns casos o carcinoma hepatocelular (Ramai et al., 2021). 
Por outro lado, ainda são escassas as opções terapêuticas para o tratamento das doenças do fígado, sendo a alteração do estilo de vida um grande aliado no controle do estabelecimento e da progressão dessas patologias.

Fisiologicamente, mediante estímulos deletérios constantes, a esteatose hepática se estabelece e avança na sua sintomatologia, para isso foi postulado em 1998 a teoria dos dois eventos (two-hit theory) para explicar os mecanismos de progressão da doença (Day \& James, 1998). Segundo essa teoria, perturbações negativas ao organismo acarretam em alterações metabólicas e ao acúmulo lipídico. Entre os estímulos negativos que atuam no organismo afetando a funcionalidade do fígado tem-se a resistência à insulina e as lesões nos hepatócitos causados por diferentes estímulos, inclusive pela influência dos agroquímicos. Esses, por sua vez, dão início ao segundo evento de progressão da esteatose ou DHGNA, que se caracterizam os distúrbios mitocondriais, estresse do retículo endoplasmático, apoptose hepatocelular, produção exacerbada de citocinas e outros elementos pró-inflamatórios, que podem progredir para esteatohepatite (necroinflamação) e subsequentemente desencadearem mecanismos de fibrogênese (Fang et al., 2018; Bovi et al., 2021). Atualmente, a teoria que subsidia o desenvolvimento das doenças hepáticas é a teoria dos múltiplos eventos (multiple-hit theory), que inclui a predisposição genética e fatores ambientais como indutores de progressão da esteatose (Fang et al., 2018; Bovi et al., 2021). O fator ambiental, enquanto um dos pontos desencadeadores da esteatose hepática não alcóolica era, até pouco tempo, desconhecido da comunidade científica, entretanto, estudos recentes apontam cada vez mais que os poluentes orgânicos persistentes e seus metabólitos são promotores de disfunções metabólicas e hepáticas (Howell et al., 2018; Armstrong \& Guo, 2019; Nagaraju et al., 2020a,b).

Considerando-se que os fitossanitários podem permanecer no ambiente por longos períodos, facilitando a contaminação indireta de organismos não-alvo, pelo consumo de alimentos e água contaminados, percebe-se que toda a sociedade está vulnerável aos agentes químicos (OPAS/OMS, 1996; Kim et al., 2019; Ravula \& Yenugu, 2021). Em estudo realizado pela ANVISA no Programa de Análise de Resíduos de Agrotóxicos em Alimento (2017/2018), contaminações por agrotóxicos de diferentes categorias foram encontradas em níveis limites insatisfatórios em aproximadamente 23\% das 4616 amostras avaliadas. Problemas similares foram reportados também em diferentes países; em 2018, um monitoramento de contaminantes e poluentes ambientais realizados pelo Programa de Monitoramento de Resíduos de Pesticidas da Food and Drug Administration (FDA) dos Estados Unidos da América (EUA), avaliou 2.956 amostras de produtos alimentares importados de 91 países diferentes e 17,4\% dos itens apresentavam considerável contaminação (FDA, 2020). Essas análises reforçam que o uso inadvertido desses agentes químicos vem causando problemas globais à medida que afetam os indivíduos, comprometendo a saúde da população. Torna-se, portanto, urgente o monitoramento e o controle do uso dessas substâncias (OPAS/OMS, 1996; Lopes \& Albuquerque, 2018; Santos \& Pereira, 2020).

Pelas observações apontadas, nota-se que toda a população está sujeita aos efeitos deletérios dos fitossanitários. Especialmente no Brasil, aonde a utilização desses compostos químicos é importante para a economia do país, uma maior conscientização dos trabalhadores e de seus empregadores, quanto aos procedimentos seguros na manipulação dos pesticidas deve ser adotada. Aliado a esse fator, maior rigidez nas fiscalizações do uso e nas liberações a comercialização dos fitossanitários, poderá contribuir com o controle de morbidades e comorbidades que afetam a população em decorrência do mal uso dos agroquímicos. Como exemplificação temos os agricultores de culturas convencionais que se expõem rotineiramente aos pesticidas. Esses apresentam, em sua maioria, alterações em seus biomarcadores metabólicos em exames clínicos de rotina tais como mensuração de níveis de colesterol, glicemia, transaminase oxalacética (TGO) e transaminase pirúvica (TGP); alterações essas que em conjunto podem resultar em uma maior predisposição ao desenvolvimento de doenças hepáticas (Kongtip et al., 2020) e outras comorbidades correlatas. Em geral, vários estudos corroboram essas observações deletérias da hepatoxicidade dos fitossanitários. Em Ravula \& Yenugu (2021) os autores relataram a capacidades dos piretróides de causar toxicidade no sistema imunológico e um desequilíbrio no estado oxidante-antioxidante; outros estudos 
apontam a capacidade do químico em induzir danos ao DNA e a morte celular, acarretando em danos sistêmicos ao organismo e hepatotoxicidade (Silvério et al., 2020). Além disso, em uma análise transversal de 847 residentes de uma área altamente contaminada com pesticidas organoclorados, observou-se uma alta correlação entre os biomarcadores de exposição e a alteração de parâmetros hepáticos, indicando inflamação e danos às células do fígado (Freire et al., 2015). Ainda, nesse estudo foi apontado que na Cidade dos Meninos, município de Duque de Caxias - RJ, existem várias desordens hematológicas e hepáticas em considerável número de indivíduos da região, uma vez que seus moradores são altamente expostos a agentes químico, organoclorados, oriundos de empresas sintetizadoras de tais compostos químicos que lá se fixaram em 1950, sugerindo falhas na fiscalização do uso e manipulação de tais compostos agrícolas. Outros estudos apontam a mesma problematização (Souza et al., 2011; Lopes \& Albuquerque (2018) que se insere em um importante e complexo sistema de políticas públicas correlatas a economia e a saúde pública e que elencamos ao longo do texto. Medidas educativas e de conscientização da população e seus governantes se faz urgente.

\section{Considerações Finais}

Todas as sociedades são dependentes de legislações e regulamentos que norteiam as diretrizes econômicas dos países aonde estas se inserem. Sendo o Brasil, dependente economicamente da exportação de matéria prima e produtos agropecuários, este se classifica com um país ainda em desenvolvimento. Dentro desse contexto, a legislação brasileira favorece o uso de insumos agrícolas, que classifica o país como o maior consumidor mundial de fitossanitários. Considerando-se o uso exacerbado desses produtos químicos, defendida por pequenos, médios e grandes produtores agrícolas, consequências adversas ao meio ambiente, à saúde dos próprios agricultores e da população em geral são observadas. Nesse estudo foram apresentados os agentes químicos mais consumidos em território nacional e as consequências de seu uso desmedido, como forma de alerta de sua periculosidade. Dentre os vários malefícios causados pelos fitossanitários à saúde humana, temos o dano ao fígado e o consequente desenvolvimento das patologias hepáticas. Caracterizadas pela Organização Mundial da Saúde como uma das 10 causas primárias de morte em diferentes países, essas anomalias, que possuem várias etiologias entre as quais a exposição às toxinas ambientais, fere o metabolismo humano desregulando a homeostase corporal, uma vez que o órgão é crucial para o controle de mecanismos de detoxificação e equilíbrio energético. O desequilíbrio do órgão acarreta em aumento do estresse oxidativo, assim como em alterações no metabolismo glicolítico e lipídico do fígado, acarretando no acúmulo de triglicerídeos e o desenvolvimento de quadros de esteatose, os quais podem progredir a quadros clínico mais graves como a cirrose e o hepatocarcinoma. Essas patologias, que vem aumentando em número nas últimas décadas, tem os fitossanitários como um coadjuvante no estabelecimento das anomalias, que se tornaram um problema de saúde pública, que pode ser contornado pelo endurecimento da legislação e dos processos de fiscalização do uso dos agrotóxicos, assim como pelo incentivo à educação dos trabalhadores rurais, no sentido de uma maior conscientização do uso desses fitossanitários, tanto no manuseio, no descarte, como na quantidade dos produtos químicos usados. Somente com políticas públicas fortes, aliada a conscientização da população sobre a periculosidade desses produtos agrícolas, é que os riscos à sociedade poderão ser diminuídos, e dessa maneira direcionar o uso dos fitossanitários de maneira positiva a economia e à sociedade como um todo. Portanto, a população precisa participar mais assertivamente das mudanças necessárias ao contexto social.

\section{Agradecimentos}

Ao PIBIC - UNESP 1/2020, a Fundação de Amparo à Pesquisa do Estado de São Paulo (FAPESP 2018/05286-3) e a Msc. Camila C.C. Pansa pela correção do espanhol. 


\section{Referências}

Alamri, Z. Z. (2018). The role of liver in metabolism: An updated review with physiological emphasis. International Journal of Basic \& Clinical Pharmacology, 7(11), 2271-2276.

Pereira, A. S., Shitsuka, D. M., Parreira, F. J., \& Shitsuka, R. (2018). Metodologia da pesquisa científica. UFSM. https://repositorio.ufsm.br/bitstream/h andle/1/15 824/Lic_Computacao_Metodologia-Pesquisa-Cientifica.pdf?sequence=1.

Almeida, M. D., Cavendish, T. A., Bueno, P. C., Ervilha, I. C., Gregório, L. D. S., Kanashiro, N. B. O., \& Carmo, T. F. M. do. (2017). A flexibilização da legislação brasileira de agrotóxicos e os riscos à saúde humana: Análise do Projeto de Lei no 3.200/2015. Cadernos de Saúde Pública, 33(7), 1-10.

Aranha, M. L. G., Garcia, M. S., de Carvalho Cavalcante, D. N., Silva, A. P. G., Fontes, M. K., Gusso-Choueri, P. K., \& Perobelli, J. E. (2021). Biochemical and histopathological responses in peripubertal male rats exposed to agrochemicals isolated or in combination: A multivariate data analysis study. Toxicology, $447,1-52$.

Armstrong, L. E., \& Guo, G. L. (2019). Understanding environmental contaminants' direct effects on non-alcoholic fatty liver disease progression. Current Environmental Health Reports, 6(3), 95-104.

Bano, F., \& Mohanty, B. (2020). Thyroid disrupting pesticides mancozeb and fipronil in mixture caused oxidative damage and genotoxicity in lymphoid organs of mice. Environmental Toxicology and Pharmacology, 79, 1-8.

Barbosa, E. A., Silva, I. M. da, França, A. C., Silva, E. de B., \& Matos, C. da C. de. (2020). Evaluation of leaf and root absorptions of glyphosate in the growth of coffee plants. Arquivos do Instituto Biológico, 87, 1-8.

Bianchi, S., Nottola, S. A., Torge, D., Palmerini, M. G., Necozione, S., \& Macchiarelli, G. (2020). Association between female reproductive health and mancozeb: Systematic review of experimental models. International Journal of Environmental Research and Public Health, 17(7), 1-15.

Bonmatin, J. M., Giorio, C., Girolami, V., Goulson, D., Kreutzweiser, D. P., Krupke, C., Liess, M., Long, E., Marzaro, M., Mitchell, E. A. D., Noome, D. A., Simon-Delso, N., \& Tapparo, A. (2015). Environmental fate and exposure; neonicotinoids and fipronil. Environmental Science and Pollution Research, 22(1), $35-67$.

Bovi, A. P. D., Marciano, F., Mandato, C., Siano, M. A., Savoia, M., \& Vajro, P. (2021). Oxidative stress in non-alcoholic fatty liver disease. An updated mini review. Frontiers in Medicine, 8, 595371.

Carrão, D. B., Habenchus, M. D., de Albuquerque, N. C. P., da Silva, R. M., Lopes, N. P., \& de Oliveira, A. R. M. (2019). In vitro inhibition of human CYP2D6 by the chiral pesticide fipronil and its metabolite fipronil sulfone: Prediction of pesticide-drug interactions. Toxicology Letters, 313, $196-204$.

Chang, Y.-N., \& Tsai, T.-H. (2020). Preclinical transplacental transfer and pharmacokinetics of fipronil in rats. Drug Metabolism and Disposition, 48(10), $886-893$.

Chielle, E. O., Bergmann, W. C. K., \& Pereira, D. L. (2015). Avaliação da expressão sérica da enzima colinesterase e de marcadores bioquímicos hepáticos e renais em plantadores de tabaco. Unoesc \& Ciência - ACBS, 6(2), 153-162.

Cui, C., Xie, X., Wang, L.Y., Wang, R.L., Lei, W., Lv, J., \& Zhou, Q.-Y. (2020). Photosynthetic index and nitrogen assimilation in rapeseed seedlings transplanted in soil with ammonium glufosinate. Ciência Rural, 50(4), 1-10.

Day, C. P., \& James, O. F. W. (1998). Steatohepatitis: A tale of two "hits”? Gastroenterology, 114(4), 842-845.

Dutra, R. M. S., \& Souza, M. M. O. de. (2017). Impactos negativos do uso de agrotóxicos à saúde humana. Hygeia - Revista Brasileira de Geografia Médica e da Saúde, 13(24), 127-140.

Fang, Y. L., Chen, H., Wang, C. L., \& Liang, L. (2018). Pathogenesis of non-alcoholic fatty liver disease in children and adolescence: From "two hit theory" to "multiple hit model". World Journal of Gastroenterology, 24(27), 2974-2983.

Faria, N. M. X. (2012). Modelo de desenvolvimento, agrotóxicos e saúde: Prioridades para uma agenda de pesquisa e ação. Revista Brasileira de Saúde Ocupacional, 37(125), 31-39.

Ferreira, V. B., Silva, T. T. C., Garcia, S. R. M. C., \& Srur, A. U. O. S. (2018). Estimativa de ingestão de agrotóxicos organofosforados pelo consumo de frutas e hortaliças. Cadernos Saúde Coletiva, 26(2), 216-221.

Food and Drug Administration. (2020). Pesticide Residue Monitoring Program Fiscal Year 2018 Pesticide Report. EUA: Autor. Recuperado de https://www.fda.gov/media/140802/download

Freire, C., Koifman, R. J., \& Koifman, S. (2015). Hematological and hepatic alterations in brazilian population heavily exposed to organochlorine pesticides. Journal of Toxicology and Environmental Health, Part A, 78(8), 534-548.

Freitas, L. M., Valadares, L. P. A. Camozzi, M. G. M., Oliveira P. G., Machado M. R. F., \& Lima F. C. (2019). Animal models in the neurotoxicology of 2,4D. Human \& Experimental Toxicology, 38(10), 1178-1182.

Gil, A. C. (2010). Como elaborar projetos de pesquisa. (5a ed.), Atlas.

Gil, A. C. (2008). Métodos e técnicas de pesquisa social. (6a ed.), Atlas.

Gonçalves, O. S., Silva, M. de F. R. da, \& Martins, P. F. (2020). Glyphosate-induced impact on the functional traits of the Bacillus sp. FC1 isolate. Pesquisa Agropecuária Tropical, 50, 1-7. 
Guimarães-Cestaro, L., Martins, M. F., Martínez, L. C., Alves, M. L. T. M. F., Guidugli-Lazzarini, K. R., Nocelli, R. C. F., \& Teixeira, É. W. (2020). Occurrence of virus, microsporidia, and pesticide residues in three species of stingless bees (Apidae: Meliponini) in the field. The Science of Nature, 107(3), 114.

Gusmão, L. C. de, Ribeiro, J. C. J., \& Custódio, M. M. (2018). Segurança alimentar e agrotóxicos: A situação do glifosato perante o princípio da precaução. Veredas do Direito: Direito Ambiental e Desenvolvimento Sustentável, 15(31), 95-125.

He, B., Ni, Y., Jin, Y., \& Fu, Z. (2020). Pesticides-induced energy metabolic disorders. Science of The Total Environment, 729, 1-9.

Hołyńska-Iwan, I., \& Szewczyk-Golec, K. (2020). Pyrethroids: How they affect human and animal health? Medicina, 56(11), 1-5.

Howell, G. E., McDevitt, E., Henein, L., Mulligan, C., \& Young, D. (2018). Alterations in cellular lipid metabolism produce neutral lipid accumulation following exposure to the organochlorine compound trans-nonachlor in rat primary hepatocytes. Environmental Toxicology. 33(9), 962-971.

Hurtado, B. S., Tresserra R. A., Vallverdú Q. A., \& Lamuela R. R. M (2019). Organic food and the impact on human health. Critical Reviews in Food Science and Nutrition, 59(4), 704-714.

Instituto Brasileiro do Meio Ambiente e dos Recursos Naturais Renováveis. (2020). Relatórios de comercialização de agrotóxicos, Os 10 ingredientes ativos mais vendidos. Brasil: Autor. https://www.ibama.gov.br/relatorios/quimicos-e-biologicos/relatorios-de-comercializacao-de-agrotoxicos\#.

Ismael, L. L., \& Rocha, E. M. R. (2019). Estimativa de contaminação de águas subterrâneas e superficiais por agrotóxicos em área sucroalcooleira, Santa Rita/PB, Brasil. Ciência \& Saúde Coletiva, 24(12), 4665-4676.

Kim, Y. A., Yoon, Y. S., Kim, H. S., Jeon, S. J., Cole, E., Lee, J., \& Cho, Y. H. (2019). Distribution of fipronil in humans, and adverse health outcomes of in utero fipronil sulfone exposure in newborns. International Journal of Hygiene and Environmental Health, 222(3), 524-532.

Klingelhöfer, D., Braun, M., Brüggmann, D., \& Groneberg, D. A. (2021). Glyphosate: How do ongoing controversies, market characteristics, and funding influence the global research landscape? Science of The Total Environment, 765, 1-13.

Kongtip, P., Nankongnab, N., Kallayanatham, N., Pundee, R., Yimsabai, J., \& Woskie, S. (2020). Longitudinal study of metabolic biomarkers among conventional and organic farmers in thailand. International Journal of Environmental Research and Public Health, 17(11), 1-11.

Lara, S. S. de, Pignati, W. A., Pignatti, M. G., Leão, L. H. da C., \& Machado, J. M. H. (2019). A agricultura do agronegócio e sua relaçâo com a intoxicação aguda por agrotóxicos no brasil. Hygeia - Revista Brasileira de Geografia Médica e da Saúde, 15(32), 1-19.

Leemans, M., Couderq, S., Demeneix, B., \& Fini, J.-B. (2019). Pesticides with potential thyroid hormone-disrupting effects: A review of recent data. Frontiers in Endocrinology, 10, 1-29.

Lei n. 7.802, de 11 de julho de 1989. Dispõe sobre a Pesquisa, a Experimentação, a Produção, a Embalagem e Rotulagem, o Transporte, o Armazenamento, a Comercialização, a Propaganda Comercial, a Utilização, a Importação, a Exportação, o Destino Final dos Resíduos e Embalagens, o Registro, a Classificação, o Controle, a Inspeção e a Fiscalização de Agrotóxicos, seus Componentes e Afins, e dá outras Providências. http://www.planalto.gov.br/ccivil_03/leis/17802.htm.

Lentola, A., Giorio, C., Petrucco Toffolo, E., Girolami, V., \& Tapparo, A. (2020). A new method to assess the acute toxicity toward honeybees of the abrasion particles generated from seeds coated with insecticides. Environmental Sciences Europe, 32(93), 1-10.

Li, X., Ma, W., Li, H., Zhang, Q., \& Ma, Z. (2020). Determination of residual fipronil and its metabolites in food samples: A review. Trends in Food Science \& Technology, 97, 185-195.

Liang, S., Zhao, Z., Fan, C., Xu, J., Li, H., Chang, Q., \& Pang, G. (2019). Fipronil residues and risk assessment of Chinese marketed fruits and vegetables: A long-term investigation over 6 years. Food Control, 106, 1-19.

Lima, M. B. S. (2020). Aspectos sociobiodiversos do novo marco regulatório para agrotóxicos publicado pela Agência Nacional de Vigilância Sanitária (Anvisa). Salvador: Universidade Católica do Salvador (UCSAL).

Lopes, C. V. A., \& Albuquerque, G. S. C. de. (2018). Agrotóxicos e seus impactos na saúde humana e ambiental: Uma revisão sistemática. Saúde em Debate, 42(117), 518-534.

Lopes, C. V. A., \& Albuquerque, G. S. C. de. (2021). Desafios e avanços no controle de resíduos de agrotóxicos no Brasil: 15 anos do Programa de Análise de Resíduos de Agrotóxicos em Alimentos. Cadernos de Saúde Pública, 37(2), 1-14.

Lozano, V. L., Allen Dohle, S., Vera, M. S., Torremorell, A., \& Pizarro, H. N. (2020). Primary production of freshwater microbial communities is affected by a cocktail of herbicides in an outdoor experiment. Ecotoxicology and Environmental Safety, 201, 1-11.

Marcato, A. C. C., Souza, C. P., \& Fontanetti, C. S. (2017). Herbicide 2,4-d: A review of toxicity on non-target organisms. Water, Air, \& Soil Pollution, $228(3), 1-12$.

Matsuo, N. (2019). Discovery and development of pyrethroid insecticides. Proceedings of the Japan Academy, Series B, 95(7), 378-400.

Medeiros, H. C. D., Constantin, J., Ishii-Iwamoto, E. L., \& Mingatto, F. E. (2015). Effect of fipronil on energy metabolism in the perfused rat liver. Toxicology Letters, 236(1), 34-42.

Meftaul, I. Md., Venkateswarlu, K., Dharmarajan, R., Annamalai, P., Asaduzzaman, M., Parven, A., \& Megharaj, M. (2020). Controversies over human health and ecological impacts of glyphosate: Is it to be banned in modern agriculture? Environmental Pollution, 263, 1-72.

Mejía-Carmona, K., Maciel, E. V. S., \& Lanças, F. M. (2020). Miniaturized liquid chromatography applied to the analysis of residues and contaminants in food: A review. Electrophoresis, 41(20), 1680-1693. 
Mendes, C. R. A., Mendes, C. E. P., Santos, F. S. E. D., Luz, K. S. R., \& Santana L. P. (2019). Agrotóxicos: Principais classificações utilizadas na agricultura brasileira - uma revisão de literatura. Revista Maestria, 17, 95-107.

Mesa, Y. P. L. (2020). The decision-making process of synthetic pesticide use in agricultural communities in Colombia: A grounded theory approach. Revista Facultad Nacional de Salud Pública, 38(2), 1-7.

Mesnage, R., Renney, G., Séralini, G.-E., Ward, M., \& Antoniou, M. N. (2017). Multiomics reveal non-alcoholic fatty liver disease in rats following chronic exposure to an ultra-low dose of Roundup herbicide. Scientific Reports, 7(1), 1-15.

Mills, P. J., Caussy, C., \& Loomba, R. (2020). Glyphosate excretion is associated with steatohepatitis and advanced liver fibrosis in patients with fatty liver disease. Clinical Gastroenterology and Hepatology, 18(3), 741-743.

Ministério Público Federal. (2015, December 4). MPF/DF reforça pedido para que glifosato seja banido do mercado nacional. Jusbrasil. https://mpf.jusbrasil.com.br/noticias/263961687/mpf-df-reforca-pedido-para-que-glifosato-seja-banido-do-mercado-nacional

Miranda, D. C. (2012). Alta demanda global por frutas e vegetais. [Dissertação de mestrado, Universidade Federal de Viçosa]. LocusUFV. https://www.locus.ufv.br/bitstream/handle/123456789/2349/texto\%20completo.pdf?sequence=1.

Mukherjee, S., \& Gupta, R. D. (2020). Organophosphorus nerve agents: Types, toxicity, and treatments. Journal of Toxicology, 2020, 1-16.

Nagaraju, R., Joshi, A. K. R., Vamadeva, S. G., \& Rajini, P. S. (2020a). Deregulation of hepatic lipid metabolism associated with insulin resistance in rats subjected to chronic monocrotophos exposure. Journal of Biochemical and Molecular Toxicology, 34(8), 1-9.

Nagaraju, R., Joshi, A., Vamadeva, S., \& Rajini, P. (2020b). Effect of chronic exposure to monocrotophos on white adipose tissue in rats and its association with metabolic dyshomeostasis. Human \& Experimental Toxicology, 39(9), 1190-1199.

Nascimento, D. Z. do, Marques, G. M., \& Trevisol, D. J. (2019). O desafio das agências reguladoras ao redor do mundo no uso do glifosato. Saúde e Sociedade, 28(4), 297-298.

Neves, P. D. M., Mendonça, M. R., Bellini, M., \& Pôssas, I. B. (2020). Intoxicação por agrotóxicos agrícolas no estado de Goiás, Brasil, de 2005-2015: Análise dos registros nos sistemas oficiais de informação. Ciência \& Saúde Coletiva, 25(7), 2743-2754.

Organização Pan-Americana da Saúde \& Organização Mundial da Saúde (OPAS/OMS). (1996). Manual de vigilância da saúde de populações expostas a agrotóxicos. Brasília.

Pandey, A., Dabhade, P., \& Kumarasamy, A. (2019). Inflammatory effects of subacute exposure of roundup in rat liver and adipose tissue. Dose-Response, $17(2), 1-11$.

Pignati, W. A., Lima, F. A. N. de S. e, Lara, S. S. de, Correa, M. L. M., Barbosa, J. R., Leão, L. H. da C., \& Pignatti, M. G. (2017). Distribuição espacial do uso de agrotóxicos no Brasil: Uma ferramenta para a Vigilância em Saúde. Ciência \& Saúde Coletiva, 22(10), 3281-3293.

Portier, C. J. (2020). A comprehensive analysis of the animal carcinogenicity data for glyphosate from chronic exposure rodent carcinogenicity studies. Environmental Health, 19(1), 1-18.

Porto, M. F., \& Soares, W. L. (2012). Modelo de desenvolvimento, agrotóxicos e saúde: um panorama da realidade agrícola brasileira e propostas para uma agenda de pesquisa inovadora. Revista Brasileira de Saúde Ocupacional, 37(125), 31-39.

Pozzetti, V. C., Cruz dos Santos, U. A. C., \& Michiles, M. P. (2019). O direito humano à alimentação saudável: Da revolução verde ao projeto de lei de proteção de cultivares (PL No 827/2015). Relações Internacionais no Mundo Atual, 2(23), 390-410.

Qin, J., Ru, S., Wang, W., Hao, L., Ru, Y., Wang, J., \& Zhang, X. (2020). Long-term bisphenol S exposure aggravates non-alcoholic fatty liver by regulating lipid metabolism and inducing endoplasmic reticulum stress response with activation of unfolded protein response in male zebrafish. Environmental Pollution, $263,1-20$.

Ramai, D., Tai, W., Rivera, M., Facciorusso, A., Tartaglia, N., Pacilli, M., Ambrosi, A., Cotsoglou, C., \& Sacco, R. (2021). Natural progression of nonalcoholic steatohepatitis to hepatocellular carcinoma. Biomedicines, 9(2), 1-16.

Ramos, L. F., Silva, C. M., Pansa, C. C., \& Moraes, K. C. M. (2021). Non-alcoholic fatty liver disease: Molecular and cellular interplays of the lipid metabolism in a steatotic liver. Expert Review of Gastroenterology \& Hepatology, 15(1), 25-40.

Ravula, A. R., \& Yenugu, S. (2021). Effect of oral administration of a mixture of pyrethroids at doses relevant to human exposure on the general and male reproductive physiology in the rat. Ecotoxicology and Environmental Safety, 208, 1-11.

Roques, B. B., Lacroix, M. Z., Puel, S., Gayrard, V., Picard-Hagen, N., Jouanin, I., Perdu, E., Martin, P. G., \& Viguié, C. (2012). Cyp450-dependent biotransformation of the insecticide fipronil into fipronil sulfone can mediate fipronil-induced thyroid disruption in rats. Toxicological Sciences, 127(1), 2941.

Runkle, J., Flocks, J., Economos, J., \& Dunlop, A. L. (2017). A systematic review of Mancozeb as a reproductive and developmental hazard. Environment International, 99, 29-42.

Sabarwal, A., Kumar, K., \& Singh, R. P. (2018). Hazardous effects of chemical pesticides on human health-Cancer and other associated disorders. Environmental Toxicology and Pharmacology, 63, 103-114.

Sadaria, A. M., Labban, C. W., Steele, J. C., Maurer, M. M., \& Halden, R. U. (2019). Retrospective nationwide occurrence of fipronil and its degradates in U.S. wastewater and sewage sludge from 2001-2016. Water Research, 155, 465-473. 
Salla, B. F. G., Bracht, L., Valderrama Parizotto, A., Comar, J. F., Peralta, R. M., Bracht, F., \& Bracht, A. (2019). Kinetics of the metabolic effects, distribution spaces and lipid-bilayer affinities of the organo-chlorinated herbicides 2,4-D and picloram in the liver. Toxicology Letters, 313, $137-149$.

Santos, C. F., Otesbelgue, A., \& Blochtein, B. (2018). The dilemma of agricultural pollination in Brazil: Beekeeping growth and insecticide use. PLOS ONE, 13(7), 1-13.

Santos, C., \& Pereira, D. (2020). Da responsabilização por danos à saúde decorrentes do uso de agrotóxicos. Revista Direito Ambiental e Sociedade, 20(1), $7-$ 28

Seshoka, M., van Zijl, M., Aneck-Hahn, N., \& Barnhoorn, I. (2021). Endocrine-disrupting activity of the fungicide mancozeb used in the Vhembe District of South Africa. African Journal of Aquatic Science, 46(1), 100-109.

Shafeeq, S., \& Mahboob, T. (2020). Magnesium supplementation ameliorates toxic effects of 2,4-dichlorophenoxyacetic acid in rat model. Human \& Experimental Toxicology, 39(1), 47-58.

Silva, L. C. M., Moreira, R. A., Pinto, T. J. S., Ogura, A. P., Yoshii, M. P. C., Lopes, L. F. P., Montagner, C. C., Goulart, B. V., Daam, M. A., \& Espíndola, E. L. G. (2020). Acute and chronic toxicity of 2,4-D and fipronil formulations (Individually and in mixture) to the Neotropical cladoceran Ceriodaphnia silvestrii. Ecotoxicology, 29(9), 1462-1475.

Silvério, A. C. P., Martins, I., Nogueira, D. A., Mello, M. A. S., Loyola, E. A. C. de, \& Graciano, M. M. de C. (2020). Assessment of Primary Health Care for rural workers exposed to pesticides. Revista de Saúde Pública, 54, 9.

Silverio, A. M., \& Pinheiro, P. B. (2019). A biociência dos agrotóxicos e seu impacto na saúde. Revista Ouricuri, 9(2), 16-33.

Soudani, N., Chaâbane, M., Ghorbel, I., Elwej, A., Boudawara, T., \& Zeghal, N. (2019). Glyphosate disrupts redox status and up-regulates metallothionein I and II genes expression in the liver of adult rats. Alleviation by quercetin. General physiology and biophysics, 38(02), $123-134$.

Souza, A., Medeiros, A. R., Souza, A. C., WinkIonara, M., Siqueira, R., Ferreira, M. B. C. F., Fernandes, L., Hidalgo, M. P, L., Torres, I. L., S. T. (2011). Avaliação do impacto da exposição a agrotóxicos sobre a saúde de população rural: Vale do Taquari (RS, Brasil). Ciência \& Saúde Coletiva, 16 (8), 3519-3528.

Taveira, B. L. S., \& Albuquerque, G. S. C. de. (2018). Análise das notificações de intoxicações agudas, por agrotóxicos, em 38 municípios do estado do Paraná. Saúde em Debate, 42(spe4), 211-222.

Tichati, L., Trea, F., \& Ouali, K. (2020). Potential role of selenium against hepatotoxicity induced by 2,4-dichlorophenoxyacetic acid in albino wistar rats. Biological Trace Element Research, 194(1), 228-236.

Trefts, E., Gannon, M., \& Wasserman, D. H. (2017). The liver. Current Biology, 27(21), R1147-R1151.

Vasconcellos, P. R. O., Rizzotto, M. L. F., Machineski, G. G., \& Costa, R. M. (2019). Condições da exposição a agrotóxicos de portadores da doença de Parkinson acompanhados no ambulatório de neurologia de um hospital universitário e a percepção da relação da exposição com o adoecimento. Saúde em Debate, 43(123), 1084-1094.

Vicini, J. L., Reeves, W. R., Swarthout, J. T., \& Karberg, K. A. (2019). Glyphosate in livestock: Feed residues and animal health1. Journal of Animal Science, 97(11), 4509-4518.

Vilca, F. Z., Zamalloa Cuba, W. A., Nazato, C., \& Tornisielo, V. L. (2017). Análise de resíduos de agrotóxicos organoclorados em morango usando o método QuEChERS com CG- $\mu$ ECD. Revista de Investigaciones Altoandinas, 19(1), 5-10.

Wahlang, B., Jin, J., Beier, J. I., Hardesty, J. E., Daly, E. F., Schnegelberger, R. D., Falkner, K. C., Prough, R. A., Kirpich, I. A., \& Cave, M. C. (2019). Mechanisms of environmental contributions to fatty liver disease. Current Environmental Health Reports, 6(3), 80-94.

World Health Organization. (2020). The top 10 causes of death. Who.Int.https://www.who.int/news-room/fact-sheets/detail/the-top-10-causes-of-death.

Zeng, X., Ding, X., Pu, Y., Jiang, H., Du, Z., \& Jiang, W. (2020). Banana condensed tannins scavenge glyphosate in aqueous solution through non-covalent interactions. $L W T, 131,1-6$.

Zhang, B., Zhang, L., He, L., Yang, X., Shi, Y., Liao, S., Yang, S., Cheng, J., \& Ren, T. (2018). Interactions of fipronil within fish and insects: Experimental and molecular modeling studies. Journal of Agricultural and Food Chemistry, 66(23), 5756-5761.

Zuanazzi, N. R., Ghisi, N. de C., \& Oliveira, E. C. (2020). Analysis of global trends and gaps for studies about 2,4-D herbicide toxicity: A scientometric review. Chemosphere, 241, 1-12. 